\title{
Silent coronary artery disease in type 2 diabetes: a narrative review on epidemiology, risk factors, and clinical studies
}

\author{
Saula Vigili de Kreutzenberg*(i) \\ Metabolic Disease Unit, Department of Medicine-DIMED, University of Padova, 35128 Padova, Italy \\ *Correspondence: Saula Vigili de Kreutzenberg, Metabolic Disease Unit, Department of Medicine-DIMED, University of Padova, \\ Via Giustiniani, 2, 35128 Padova, Italy. saula.dekreutzenberg@unipd.it \\ Academic Editor: Giovanni Targher, University and Azienda Ospedaliera Universitaria Integrata of Verona, Italy \\ Received: September 22, 2020 Accepted: November 13, 2020 Published: February 28, 2021
}

Cite this article: Vigili de Kreutzenberg S. Silent coronary artery disease in type 2 diabetes: a narrative review on epidemiology, risk factors, and clinical studies. Explor Med. 2021;2:1-19. https://doi.org/10.37349/emed.2021.00029

\begin{abstract}
Silent coronary artery disease (CAD) is one of the manifestations of heart disease that particularly affects subjects with type 2 diabetes mellitus (T2DM). From a clinical point of view, silent CAD represents a constant challenge for the diabetologist, who has to decide whether a patient could or could not be screened for this disease. In the present narrative review, several aspects of silent CAD are considered: the epidemiology of the disease, the associated risk factors, and main studies conducted, in the last 20 years, especially aimed to demonstrate the usefulness of the screening of silent CAD, to improve cardiovascular outcomes in type 2 diabetes.
\end{abstract}

\section{Keywords}

Silent coronary artery disease, epidemiology, risk factors, screening

\section{Introduction}

Cardiovascular disease, and particularly coronary artery disease (CAD) remains the leading cause of death and morbidity in patients with diabetes mellitus [1]. This represents a primary public health problem, despite the important progressive improvement of clinical management of CAD, including new medical and surgical therapies, and the control of risk factors. Indeed, a dramatic reduction of CAD prevalence and incidence has been observed among the diabetic population, in the last 20 years [2], but in this promising scenario, a peculiar manifestation of CAD stands out, a potential life-threatening disease for the patients, that is "asymptomatic ischemic heart disease."

Silent coronary artery disease is the condition in which oxygen and nutritional support to the myocardium is lessened, usually due to the presence of an atherosclerotic narrowing of the coronary arteries, causing no pain, distress or discomfort. However, limitations of coronary artery flow reserve, and functional changes, such as endothelial dysfunction, and abnormal microcirculation could also be responsible for some myocardial hypoperfusion $[3,4]$. Usually, the presence of diabetic neuropathy, causing abnormalities of pain perception, is believed to be the main reason for asymptomatic CAD in diabetic subjects, but true mechanisms leading 
to this condition are not yet totally understood. Among proposed pathophysiologic mechanisms, attenuated sensory inputs from ischemic myocardium, and altered central processing of cardiac pain sympathetic afferent fibers [5], along with sympathetic denervation [6] have been suggested, but also abnormalities of cytokine production seem to contribute to impaired nociception [7]. A significant and strong correlation between cardiac autonomic neuropathy and silent myocardial ischemia has since long been demonstrated [8-11]. In the Detection of Silent Myocardial Ischemia in Asymptomatic Diabetic Subjects study (DIAD), an impaired cardiac autonomic function was in fact the strongest predictor of abnormal stress myocardial perfusion imaging, in diabetic patients without any history of CAD, and without clinical or instrumental manifestations of the disease [11].

Silent myocardial ischemia (SMI), and silent myocardial infarction (MI) are the two manifestations of silent CAD. Initially, the definition of SMI included three subgroups: totally silent ischemia (type I); silent ischemia after a myocardial infarction (type II); and mixed silent ischemia (type III), in which patients could present both painless and symptomatic periods of myocardial ischemia [12]. More recently, SMI was simply defined as an "objective documentation of myocardial ischemia in the absence of angina or anginal equivalents" [13] while the diagnosis of prior silent/unrecognized myocardial infarction has been recently revised in the 2018 ESC/ACC/AHA/WHF Expert Consensus Document Fourth Universal Definition of Myocardial Infarction [14]. The presence of at least one of the following criteria is considered sufficient for the diagnosis of silent MI (a) abnormal Q waves with or without symptoms in the absence of non-ischemic causes; (b) imaging evidence of loss of viable myocardium in a pattern consistent with ischemic etiology; or (c) pathoanatomical findings of a prior MI.

Then, if ischemic heart disease is manifested, it will often appear in an advanced stage, and is burdened by a very serious prognosis $[15,16]$. It is well established that diabetes mellitus represents per se a condition favoring CAD, independent of the presence of the other risk factors typically associated with CAD, such as arterial hypertension, dyslipidemia, and obesity, and it is also well-known that silent CAD is more prevalent in diabetic patients, than in non-diabetic subjects $[17,18]$. Given these premises, an early screening for silent CAD could appear an appealing tool for reducing cardiovascular complications and mortality among diabetic patients.

Silent CAD obviously remains unrecognised, if not ruled out by the application of diagnostic tool, but if it is advantageous or not to screen diabetic patients for silent CAD remains up to now a serious and unanswered question. This issue has since long been debated, but it is far from being resolved. Whether the screening is effective in reducing the cardiovascular outcomes, in patients with diabetes mellitus remains uncertain, and totally convincing evidence is lacking, despite several studies have been carried on trying to answer this primary argument. Currently available guidelines do not recommend the screening for silent CAD in asymptomatic diabetic patients, even if with a high cardiovascular risk, since the cost-effective benefits have not been clearly demonstrated by the most recent dedicated trials, and given the optimal medical treatment of all cardiovascular disease (CVD) risk factors is guaranteed [19-21].

However, there are still many uncertainties remaining on the interpretation of available results, especially linked to the selection of patient enrolled in these studies, to the various definitions of the disease, and to different methodologies employed.

\section{The clinical relevance of silent coronary artery disease in type 2 diabetes}

The importance of CAD as a relevant cause of morbidity and mortality in diabetes emerged in the second half of 1900 [22-24], and since then the interest for silent CAD as an important clinical condition for poor cardiovascular outcomes in diabetes has emerged and progressively increased [25-29]. Early data from the Framingham Heart study showed that about $50 \%$ of myocardial infarctions were totally silent, especially in diabetic individuals $[30,31]$. Later, this figure appeared to be reduced, in the follow-up study of Framingham population, but again, more than $25 \%$ of total myocardial infarctions were asymptomatic, and casually discovered during the routine biennial electrocardiographic examinations [32]. In the United Kingdom Prospective Diabetes Study (UKPDS) the prevalence of silent myocardial infarction, based on the presence 
of pathological Q waves, was of $17.5 \%$ in a population of 5,102 newly diagnosed type 2 diabetic patients (T2DM), enrolled from 1977 to 1991 [33].

Following these pieces of evidence, showing a significant proportion of previous silent myocardial infarction in diabetes, silent CAD was investigated by functional and atomic testing revealing a highly variable prevalence, ranging from around $10 \%$ to more than $50 \%[8,26,27,34-40]$.

Observed differences in the prevalence of the disease in diabetic subjects can be ascribed to several factors: (1) to a different definition of "silent CAD"; (2) to different baseline level of ischemic cardiac risk of the studied populations; (3) to the presence of micro- and macro-vascular complications of diabetes; (4) to the presence of comorbidities; (5) to diabetes duration; (6) to the methodological approaches utilized for the diagnosis of silent CAD (i.e. the sensibility and specificity of the test); and, maybe (7) to the progressive improvement in the management of diabetes itself and its associated cardiovascular (CV) risk factors.

Functional tests for the screening of silent CAD include an electrocardiogram (ECG) exercise tolerance test, exercise/pharmacological stress echocardiography, and exercise/pharmacological myocardial perfusion imaging, while anatomic tests include a coronary artery calcium scoring by electron-beam computed tomography, CT angiography, cardiac magnetic resonance imaging and positron emission tomography [41, 42] (Table 1). The choice of the screening test can increase the possibility to predict the disease. Stress myocardial perfusion imaging (MPI) and stress echocardiography are more effective than ECG stress test in detecting silent CAD [42]. Furthermore, when two tests are concordant, the positive predictive value for detection of CAD improves [43].

Table 1. Main non-invasive tests for the screening of silent CAD

\begin{tabular}{|c|c|c|c|}
\hline Test & Type & Advantages & Disadvantages \\
\hline \multirow[t]{2}{*}{ Exercise stress test } & Functional & Low cost & Low sensitivity \\
\hline & & Physiologic stress & \\
\hline \multirow[t]{3}{*}{ Stress echocardiography } & Functional & Low cost & Difficult in some patients \\
\hline & & Pharmacological/physiological stress & False negative if single vessel disease \\
\hline & & High specificity & \\
\hline \multirow[t]{2}{*}{ Radionuclide imaging } & Functional & High sensitivity & Radiation \\
\hline & & & False positive \\
\hline \multirow[t]{2}{*}{ Coronary artery calcium } & Anatomic & Non-invasive & Radiation \\
\hline & & & No stenosis evaluation \\
\hline $\begin{array}{l}\text { Coronary computed } \\
\text { tomography angiography }\end{array}$ & Anatomic & High negative predictive value & No function evaluation \\
\hline $\begin{array}{l}\text { Magnetic resonance } \\
\text { imaging }\end{array}$ & $\begin{array}{l}\text { Anatomic/ } \\
\text { functional }\end{array}$ & Expensive & Preliminary studies \\
\hline
\end{tabular}

It is also clinically relevant to underline that myocardial ischemia can resolve, as demonstrated in the DIAD study, after patients underwent intensive CV risk factor control; in follow-up of the DIAD study, resolution of ischemia was found in 79\% of 71 T2DM patients who initially had abnormal studies, after 3 years of optimal medical treatment [44]. Moreover, the prevalence of silent CAD seems to reduce over time: a French cohort of 770 T2DM, prospectively followed-up for a 10-year period, showed a progressive and steady reduction of SMI from $22.6 \%$ in $1999-2002$, to $13.7 \%$ in $2003-2005$ and to $5.9 \%$ in $2006-2009$ $(P<0.0001)$ [45].

In the next paragraph, the main studies that evaluated the prevalence of silent CAD, performed after year 2000, will be considered. In these studies, it is not always specified whether patients are diagnosed as having T2DM or type 1 diabetes mellitus (T1DM), but eventually the ratio between type 2 and type 1 diabetes is so relevant, that we can assume results are compatible with T2DM. 


\section{Epidemiology of SMI}

In the early 2000s, Miller et al. [36] conducting studies at the Mayo Clinic found that $58.6 \%$ out of 1,738 asymptomatic diabetic patients without known CAD, but with CVD risk factors had an abnormal stress single photon emission computed tomography (SPECT) imaging scan; in 18\% of these patients a high-risk diagnostic test was observed [39]. In the Italian study by Faglia et al. [40], a positive exercise electrocardiogram or dipyridamole stress echocardiography was observed in $21.4 \%$ out of 141 T2DM without known CAD, but at high CV risk. A similar figure was obtained in the DIAD study, in which the prevalence of an abnormal myocardial perfusion imaging, among 522 T2DM patients aged 50-75 years, but not necessarily with CV risk factors, was of 22\% [11]. In the study conducted by Zellweger et al. [46], published in the same period, aimed to assess the prevalence of CAD in asymptomatic diabetic patients at relatively low risk of CAD, using a dual-isotope myocardial perfusion test (MPS), the disease was much more common, being diagnosed in $39 \%$ out of 826 asymptomatic diabetic individuals. In a contemporary study by Anand et al. [47], the screening of SMI, combining coronary artery calcium (CAC) imaging and selective myocardial perfusion scintigraphy (performed when CAC $>100$ Agatston units), showed an abnormal test (CAC > 10 Agatston units) in $46.3 \%$ out of 510 asymptomatic diabetic patients, thus demonstrating the presence of a significant coronary atherosclerosis in slightly less than the half of them. De Luca et al. [48] described a prevalence of SMI of about $1 / 3$ in 189 patients with diabetes and no history of angina, having a treadmill exercise sestamibi stress test. In this study, SMI was diagnosed in 33\% T2DM patients, compared to $15 \%$ of 191 non-diabetic patients. Nine studies carried out from 1999 to 2010 were considered in a metanalysis by Zhang et al. [49]; in this analysis, the prevalence of SMI detected by SPECT in the pooled sample was $26.1 \%$.

The Basel Asymptomatic high-Risk Diabetics' Outcome Trial (BARDOT) was published in 2011; in this trial the prevalence of abnormal MPS was found still elevated, being of $22 \%$ among 400 diabetic patients without prior CAD, but at high CV risk [50]. In the contemporary Do You Need to Assess Myocardial Ischemia in Type-2 diabetes (DYNAMIT) study, SMI detected by a bicycle exercise test or dipyridamole single photon emission computed tomography (SPECT) was present or uncertain in $21.5 \%$ out of 316 screened T2DM patients without known CAD, but with at least two additional cardiovascular risk factors [51]. In the FACTOR-64 trial [52], a coronary computed tomography angiography (CCTA) was performed in 395 diabetic subjects, who were at high risk, but with an excellent medical management of CV risk factors; the degree of coronary involvement was categorized into 4 prespecified subgroups: from none/minimal $<10 \%$ stenosis and minimal or no evidence of plaque and CAC score $\leq 10)$, to mild (10-49\% stenosis in any coronary artery or CAC score $>10-100)$, to moderate $(50-69 \%$ stenosis or CAC score $>100)$, and severe stenosis $(\geq 70 \%$ stenosis in at least 1 major proximal or large coronary artery). Eleven percent out of the subjects showed severe stenosis at CCTA, $12 \%$ moderate, and $46 \%$ mild, while only $31 \%$ had a normal exam. Surprisingly, in the monocentric Italian DADDY-D (Does coronary Atherosclerosis Deserve to be Diagnosed earlY in Diabetic patients?) [37], silent CAD, investigated by exercise tolerance testing, was found in only $7.6 \%$ out of 520 T2DM patients, with no clinical CAD, but with a CV risk score $\geq 10 \%$ according to the Italian risk chart [53]. This figure is very close to results of another Italian study, the milan study on atherosclerosis and diabetes (MiSAD) group, published 18 years before [8]. The MiSAD evaluated by exercise electrocardiogram, and if abnormal, by an exercise thallium scintigraphy, 925 T2DM; $12.1 \%$ out of the patients presented SMI at exercise ECG, but this prevalence was reduced to $6.4 \%$ if positive response to both tests was applied. It is reasonable to suppose that these results could be due to the low cardiovascular risk presented by some populations, such as those of Southern Europe.

Data from the Guedalupe Afro-Caribbean diabetic population, reported a SMI prevalence of $23.1 \%$ in a group of 147 T1DM and T2DM (93.2\% of all the patients), with CV risk factors [54]. In a Chinese study published in 2019, including 821 T2DM subjects screened by SPECT, the prevalence of SMI was 21.3\% [55]. In another small pilot Chinese study, published in 2020, the CATCH (Cardiac Magnetic Resonance for Asymptomatic Patients with Type 2 Diabetes and Cardiovascular High Risk) study, that enrolled 63 asymptomatic DM patients with a Framingham risk score $\geq 20 \%$, a silent obstructive CAD was evidenced by stress cardiovascular magnetic resonance in $20.6 \%$ of the studied patients [56]. 
A contemporary study performed in India found a treadmill test positive for SMI in $23.1 \%$ out of 338 asymptomatic T2DM subjects [57], while another Indian study that enrolled 97 T2DM observed that only $10 \%$ out of the asymptomatic patients showed evidence of SMI or silent MI at SPECT [58]. Finally, a small Saudi Arabian study evaluating 59 T2DM patients without history of CAD, but with multiple CV risk factors detected an abnormal scan in $37 \%$ of the patients who had undergone myocardial perfusion SPECT imaging [59].

Therefore, we can conclude that, apart from a few studies, the prevalence of silent CAD is similar, in different diabetic populations in the world.

The clinical burden of asymptomatic ischemic heart disease seems at least comparable to that of symptomatic CAD, if not worse. Total and cardiovascular mortality were found not significantly different in diabetic patients surviving a silent MI, with respect to survivors a symptomatic MI, in the majority of the studies [34, 60-62]. However, in a study by Zellweger et al. [46], in which the rate of annual critical ischemic events was comparable in asymptomatic diabetic patients and in diabetic patients with angina, the outcome rate was 3 times worse in patients with atypical manifestation of angina, such as the shortness of breath. Other authors found that diabetic patients with silent CAD show a higher cardiac mortality risk with respect to those with symptomatic CAD, suggesting that the reason for this poorer survival could be attributed to the lack of revascularization therapy in the former group [63]. On the other hand, in the Fremantle study, an Australian community-based observational study, the risk of cardiac death was reported lower in T2DM individuals with silent MI, than in patients with overt coronary heart disease [64]. In screening studies, unrecognized myocardial ischemia is associated with a relatively poor prognosis $[65,66]$. It is interesting to note that silent ischemia accounts for $31 \%$ of all elective coronary revascularization indications, as demonstrated in the CORONOR study (Suivi d'une cohorte de patients COROnariens stables en région NORd-Pas-de-Calais) [67], collecting data from a prospective multicenter French registry, including $31 \%$ of diabetic patients.

\section{Epidemiology of silent MI}

The prevalence of silent MI in diabetic subjects is higher than in non-diabetic, and is generally reported of $2-7 \%[17,68]$, but increases significantly with the cardiovascular risk of the patient, and depends on the diagnostic accuracy of methodology utilized, reaching 20-30\% in high risk patients evaluated by myocardial single-photon emission computed tomography or magnetic resonance [18]. The prevalence of silent CAD among diabetic subjects, observed in main studies is summarized in Table 2.

Table 2. Prevalence of silent CAD among diabetic subjects, observed in major studies

\begin{tabular}{|c|c|c|c|c|}
\hline Author (ref.), publication year & $\begin{array}{l}\text { Number of } \\
\text { subjects }\end{array}$ & $\begin{array}{l}\text { Type of } \\
\text { diabetes }\end{array}$ & Prevalence of silent CAD (\%) & Method \\
\hline Wackers et al. [11], 2004 & 522 & T2DM & 22 & Abnormal SPECT \\
\hline Anand et al. [47], 2006 & 510 & T2DM & 46.3 & Significant CAC \\
\hline Lièvre et al. [51], 2011 & 316 & T2DM & 21.5 & $\begin{array}{l}\text { Exercise test or dipyridamole } \\
\text { SPECT positive or uncertain }\end{array}$ \\
\hline Davis et al. [33], 2013 & 1,967 & T2DM & 16.6 & ECG evidence of SMI \\
\hline Zellweger et al. [50], 2014 & 400 & T2DM & 22 & Abnormal MPS \\
\hline Muhlestein et al. [52], 2014 & 395 & $\begin{array}{l}\text { T1DM } \\
\text { T2DM }\end{array}$ & $\begin{array}{l}10.7 \text { severe stenosis } \\
11.9 \text { moderate stenosis } \\
46.1 \text { mild stenosis }\end{array}$ & $\begin{array}{l}\text { Abnormal coronary computed } \\
\text { tomography angiography }\end{array}$ \\
\hline Turrini et al. [37], 2015 & 262 & T2DM & 7.6 & Silent CAD at exercise test \\
\hline Zhu et al. [55], 2019 & 614 & T2DM & 21.3 & Abnormal SPECT \\
\hline
\end{tabular}

In the UKPDS, the prevalence of silent MI in T2DM patients was $17.5 \%$ and progressively increased over time [33]. This high rate, however, could be explained by the lack of specific ECG criteria used in this study [17]. In the cohort of the Fremantle Study, a diagnostic or probable Q-wave was detected in 3.9\% 
out of 1,269 T2DM subjects investigated, representing 43.9\% of the total observed myocardial infarctions (symptomatic and silent) [64].

In an American study, silent MI diagnosed by treadmill exercise sestamibi stress test was observed in $18 \%$ of a total of 217 patients with diabetes $v s .7 \%$ of 224 patients without diabetes [48]. In this study, the prevalence of silent MI was $40 \%$ among diabetic subjects with 2-3 coronary risk factors, while $27 \%$ in patients with 0-1 coronary risk factors [48].

Kwong et al. [69] found a prevalence of myocardial scars, detected by cardiac magnetic resonance, in $28 \%$ out of 109 diabetic patients, without clinical evidence of the disease. In the Chinese CATCH study, silent myocardial infarction was detected by magnetic resonance in $7.9 \%$ of the subjects [56].

The incidence of silent MI was also investigated in several pharmacological and intervention randomized controlled trials (RCT) [18,60,70-75] enrolling patients in primary or secondary prevention, most often diagnosed using the 12-lead ECG and applying Minnesota-code criteria. In primary prevention studies, the incidence of silent MI is about $1 / 1,000$ patients-year [70, 71, 76, 77], but it increases to 4-6/1,000 patients-year in subjects in secondary prevention or in high risk subjects, such as those in the PROactive pioglitazone clinical trial. In macrovascular events [72, 73], in the IDNT (Irbesartan Diabetic Nephropathy Trial) [78], and in the FIELD (Fenofibrate Intervention and Event Lowering in Diabetes) studies [60].

Data obtained from the JPAD (Japanese Primary Prevention of Atherosclerosis with Aspirin for Diabetes) trial [76], a randomized controlled trial designed to examine the efficacy of low-dose aspirin therapy in primary prevention in T2DM patients, started in 2002 and concluded in 2008, but with a post-study followup until 2015, 25\% of all myocardial infarctions were silent, with an incidence rate for silent MI of 1.44/1,000 patients-year, and of 4.26 for symptomatic MI [79].

The FIELD study specifically aimed to determine the incidence of silent MI, and its predictors, along with the effects of fenofibrate on this outcome in a large cohort of T2DM patients [60]. Silent MI was found in 265 patients (2.7\% of all participants), with a cumulative incidence rate of 5.5/1,000 patients-year, during the 5 years of follow-up period, representing the $36.8 \%$ of all the recorded MI. The incidence of silent MI in the PROactive study $[72,73]$, that included patients with evidence of macrovascular disease, was similar, ranging from 2.9 to 5.5/1,000 patients-year [18]. In the IDNT study, that enrolled T2DM patients with hypertension, and nephropathy, the incidence of clinically unrecognized MI was 4/1,000 patient-years, in a follow-up period of 2.5 years [78].

Among more recent CVOTs (CardioVascular Outcome Trials), designed to evaluate the cardiovascular safety of sodium-glucose co-transporter-2 (SGLT2)-inhibitors and of glucagon-like receptor-1 agonists (GLP1-RA) in high cardiovascular risk T2DM individuals, silent MI was often considered, and its prevalence did not show any significant difference between treatment and placebo arms. In the EMPA-REG (Empagliflozin Reducing Excess Glucose) trial, the presence of a silent MI was analyzed in about 50\% of at high risk patients enrolled: in 2,378 patients in the empagliflozin group and in 1,211 in the placebo group [80]. In this population, the incidence rate of silent MI was 6.2/1,000 patients-year (5.4/1,000 patients-year in the placebo group and of 7.0/1,000 patients-year in the empagliflozin group, $P=0.42$ ). Silent MI was also assessed in all the participants in the LEADER (Liraglutide Effect and Action in Diabetes: Evaluation of Cardiovascular Outcome Results) trial [81] and in SUSTAIN-6 (Semaglutide in Subjects with Type 2 Diabetes) trial [82], both enrolling at high risk patients. The incidence rate of silent MI was $0.35 / 100$ patients-year in the LEADER (0.4/100 patients-year in the placebo group and 0.3/100 patients-year in the liraglutide group, $P=0.37)$ [81], and $0.17 / 100$ patients-year in the SUSATIN-6 $(0.21 / 100$ patients-year in the placebo group and $0.12 / 100$ patients-year in the semaglutide group; $P=0.37$ ] [82]. Therefore, data from recent CVOTs in T2DM on silent MI show an incidence very similar to that obtained in previous studies.

Interestingly, silent MI in T2DM was also investigated as a possible marker for CV risk prediction in 2 main studies, the UKPDS [33], and the ACCORD (Action to Control Cardiovascular Risk in Diabetes) trial [83]. Results obtained from the UKPDS led to the conclusion that silent MI was an independent predictor of future fatal MI and all-cause mortality, but failed to demonstrate a more accurate prediction of risk when added to the UKPDS risk engine [33]. On the other hand, results obtained from the ACCORD trial, where 
the prevalence of silent MI at baseline was 5.3\% among the 5,539 eligible participants (mean age $62.8 \pm$ 5.8 years), allowed to conclude that not only the presence of silent MI was associated with increased risks of all-cause mortality, cardiovascular mortality, congestive heart failure, and major coronary heart disease events, but also improved the discrimination capacity, when added in risk models [83].

\section{Factors associated with silent coronary artery disease in type 2 diabetes}

Many studies tried to identify independent predictors of silent CAD in T2DM, that could help in the selection of patients to be screened, answering one out of the pivotal questions still open, on the opportunity of screening silent CAD in diabetes. Results obtained from the different studies on predictors of SMI or silent MI are not always concordant, due to the specific characteristics of the studied populations, to their baseline $\mathrm{CV}$ risk, to the presence of diabetic micro- and macrovascular complications, to the choice of the variables to be investigated, and also, maybe to unknown genetic factors, and understudied markers.

The impact of sex differences in the diabetic population is often, but not always considered in the studies, and sometimes the results could be nullified by the small sample sizes of enrolled patients. In the general population of the Framingham [34] and the Cardiovascular Health Study [84], a higher risk of silent MI was observed in women, while recent results from the Atherosclerosis Risk in Communities (ARIC) study showed an incident rate of silent MI significantly higher in men than in women [85]. In the diabetic population, a greater prevalence of silent MI has been observed in women in the Fremantle [64], and in the UKPDS [33] studies. In the ACCORD cohort no evidence was found that silent MI, as detected by the Minnesota code, was more common in women than in men; rather, women showed a higher heart disease mortality rate compared to men [86]. Usually women complain less of chest pain and of typical symptoms of acute coronary syndrome, especially diabetic women $[87,88]$, but often asymptomatic women have a worse prognosis than asymptomatic males $[86,89]$.

Cardiac perfusion abnormalities seem to be more frequent among men than women $[36,39,46,50]$, and male sex is an independent predictor of SMI in the majority of the studies [11, 26, 36, 38, 39, 46, 70, 90]. In the DIAD study, the frequency of abnormal screening did not differ between men (24\%) and women (19\%), however women tended to show smaller MPI defects, and lower subsequent cardiac event rates with respect to men, so that the authors conclude that "symptomatic women with T2DM represent a subgroup for which screening for coronary artery disease does not appear warranted" [91]. Similarly, no difference was observed between men and women in the incidence of SMI in a Japanese study published in 2020, where women, nonetheless, experienced a worse prognosis, and only in female, but not in male, SMI was independently associated with major adverse cardiac events (MACE) [89].

ECG abnormalities are potent predictors of silent CAD. In the Milan study [8], ST-T abnormalities showed the highest odds ratio for SMI [9.27, confidence interval (CI) 4.44 to 19.38], and were the only independent predictors in women. In the DIAD study, only females showed a significant association with ischemic ST-segment depression, induced by adenosine infusion, in the presence of a normal myocardial perfusion (OR 3.4) [11]. Pathological Q waves were independently associated with a high-risk scan in the American study by Rajagopalan et al. [39]. In a more recent, small, Italian study, an abnormal ECG was the strongest, independent predictor of silent CAD in 102 asymptomatic T2DM individuals (OR 8.9, CI 1.27-62.5; $P=0.028$ ] [92].

The presence of diabetes target organ damage has been investigated in several studies, and a higher prevalence of silent CAD was demonstrated for retinopathy [20,26, 55, 93, 94], neuropathy [11, 95-100], and nephropathy [59, 101-104], as well as for peripheral vascular disease [105-112].

Diabetic retinopathy, and male gender increased the prediction of silent MI, in a French cohort of T2DM [93]. In a Chinese study of 821 T2DM, the prevalence of SMI was significantly different depending on the presence of diabetic retinopathy [55]. The percentages of SMI were 18.5\% (75/405) among patients without diabetic retinopathy, 25.2\% (37/147) among patients with non-proliferative diabetic retinopathy, and 30.6\% (19/62) among patients with proliferative retinopathy [55]. Another recent study has found that presence and degree of DR are independently associated with silent CAD, in T2DM [94]. 
Silent CAD is a specific manifestation of diabetic autonomic neuropathy [95-98], and an abnormal cardiac autonomic function, measured by heart rate variability (HRV) is significantly associated with an increased risk of mortality [98]. T2DM subjects with cardiac autonomic neuropathy (CAN) are therefore susceptible for experiencing silent CAD. When both SMI and CAN are present, the risk of major cardiac events is significantly increased [99]. Vinik et al. [95] reported a consistent association between CAN and the presence of silent myocardial ischemia. Diabetic neuropathy and cardiac autonomic function were evaluated in all the patients of the DIAD study, and an abnormal heart rate response to Valsalva manoeuvre (odds ratio 5.6), was the strongest predictor for an altered cardiac test in this cohort [11, 100].

Another powerful predictor of silent CAD morbidity and mortality is erectile dysfunction, that is an early manifestation of ischemic heart disease [105-107]. Pathophysiological mechanisms common to CAD and erectile dysfunction involve abnormalities found in both vessels and nerves, and are ascribable to endothelial dysfunction, a decrease of nitric oxide-induced vasodilation and smooth muscle relaxation, and to diabetic autonomic neuropathy $[96,113]$. T2DM with erectile dysfunction show a higher prevalence of silent CAD $[106,108]$, and the evaluation of erectile dysfunction in T2DM individuals has been suggested to be a powerful tool in improving the sensitivity of screening guidelines for SMI detection [109].

Diabetic nephropathy, is a well-known, strong predictor of CVD, and its association with silent CAD has been highlighted in several studies, even in the early stages of chronic renal disease [59, 101-104]. Microalbuminuria, a marker of incipient nephropathy, has been shown to be significantly associated with silent CAD, and is a powerful predictor of the disease [60, 100-103]. Al-Humaidi et al. [59] demonstrated that myocardial abnormalities detected by SPECT in T2DM, correlates with nephropathy. On the other hand, the majority of patients in dialytic therapy, with angiographically documented CAD, are asymptomatic [104].

Peripheral vascular disease has been shown to be independently associated with silent CAD in several studies [11, 39, 45, 108, 110, 111]. Rajagopalan et al. [39] concluded that ECG Q waves, and peripheral artery disease (OR 2.134, CI 1.150-3.961; $P=0.016$ ) were the 2 most important variables associated with high risk findings on stress SPECT, in their analysis. In the population of BARDOT trial, peripheral artery disease independently predicted an abnormal MPS (OR 2.134, CI 1.150-3.961; $P=0.016$ ) [110]. A recent prospective, multicenter study has demonstrated that the presence of carotid plaque is a predictor of silent CAD prevalence, severity, and extent in asymptomatic T2DM [111]. Therefore, the screening for carotid atherosclerosis has been recommended in identifying diabetic patients at higher risk for silent CAD [112].

Several studies have underlined the important role of a positive family history of CAD as a strong predictor of silent CAD and silent MI [26, 59, 114]. In a study by Kawano et al. [114], including 128 patients, the family history of CVD and/or long disease duration (> 11 years) were the best independent risk factors of SMI showing an OR of 1.060 and 4.000, respectively, by a multivariate analysis.

Finally, classical risk factors for ischemic heart disease, such as smoking, hypertension, hypercholesterolemia, diabetes duration have often (but not always) been demonstrated to be independently associated or predictors of silent CAD, in T2DM [90, 100, 110, 112]. The recent analysis of data of the BARDOT trial recognized, as independent predictors of an abnormal MPI, apart from male sex, and peripheral artery disease, the duration of diabetes (OR 1.049, CI 1.015-1.085; $P=0.005$ ), smoking (OR 2.064, CI 1.109-3.839; $P=0.022$ ), systolic blood pressure (OR 1.014, CI 1.00-1.03; $P=0.056$ ), and also brain natriuretic peptide (OR 1.002, CI 1.001-1.004; $P=0.005$ ) [110]. An exploratory analysis of the DIAD study, performed instead of multivariate assessment, precluded by the low number of events occurred in this study, suggested that other independent predictors of a future primary cardiac event, in addition to male sex and cardiac autonomic dysfunction, were: creatinine, peripheral vascular disease, and lowdensity lipoprotein levels [100]. Anand et. al. [47] demonstrated, in 510 asymptomatic T2DM subjects, that age, systolic blood pressure, diabetes duration, UKPDS risk score, CAC score, and extent of myocardial perfusion abnormalities were significant predictors of time to cardiovascular events. In the study by Scholte et al. [90], current smoking, duration of diabetes and the total cholesterol/HDL-cholesterol ratio were identified as independent predictors of an abnormal SPECT, in 120 asymptomatic T2DM individuals. 
Therefore, to summarise, males seem to be more susceptible to manifest silent CAD, but women seem to have a worse prognosis. Classical risk factors for CVD i.e. positive family history, age, smoke, arterial hypertension, dyslipidaemia, and the duration and control of diabetes itself can significantly contribute to the development of silent CAD in diabetes. Diabetic chronic complications either macro- or microangiopathy are also important predictors of silent CAD. In particular, the evidence of ischemic ECG abnormalities strongly suggests silent CAD in asymptomatic diabetic subjects.

In the proposed algorithm for the screening of silent CAD, the presence of organ damage in diabetes, either micro- or macroangiopathic invariably is suggested as a suitable condition to consider a patient for the screening $[19,21,115]$.

\section{Studies aimed to demonstrate the benefit of screening silent CAD in type 2 diabetes-criticisms and unmet answers}

Two important meta-analysis were published by Bauters and Lemeslein 2016 [116], and by Clerc et al. [117] in 2018, analyzing main studies aimed at demonstrating the usefulness of screening silent CAD in diabetic subjects. Five randomized trials for a total of 3,314 [116], and 3,299 [117] asymptomatic diabetic individuals were considered in these meta-analyses: the study by Faglia et al. [40] published in 2005, the DIAD study of 2009 [100], the DYNAMIT study of 2011 [51], the FACTOR-64 study of 2014 [52] and the DADDY-D study of 2015 [37]. All the studies enrolled patients with T2DM, apart from FACTOR-64, in which $12 \%$ of the subjects were T1DM.

In the analysis by Bauters and Lemesle [116], it emerged that the screening of silent CAD was unable to improve cardiovascular outcomes, with an odd ratio for all-cause death of 1.00 (95\% CI 0.67-1.50), for cardiovascular death, of 0.72 (95\% CI 0.33-1.57), for non-fatal myocardial infarction, of 0.71 (95\% CI 0.40-1.27) and for the composite cardiovascular death or non-fatal myocardial infarction, of 0.60 (95\% CI 0.23-1.52). Therefore, the conclusions of this meta-analysis were against the screening for silent CAD in diabetes.

On the other hand, the analysis by Clerc et al. [117], after considering several criticisms of the studies included in the analysis, also acknowledging that any mortality benefit can be demonstrated, concluded that "The present systematic review and meta-analysis suggests a reduction of cardiac events with the use of a CAD screening strategy in asymptomatic diabetic patients." These authors demonstrated that non-invasive imaging for CAD significantly reduced the primary composite endpoint of any cardiac event by $27 \%$, with a number needed to treat (NNT) of 56 asymptomatic T2DM, to prevent 1 cardiac event over a 4-year period, comparing this benefit to that of statin use for primary prevention of ischemic heart disease events $(-27 \%$, NNT 78) [118]. This effect was mainly driven by lower rates of non-fatal MI (-35\%) and of hospitalizations for heart failure (-39\%); however, when assessed separately, the event rates of non-fatal MI (relative risk $0.65, P=0.062$ ), and hospitalization for HF (relative risk $0.61, P=0.1$ ) were not significant.

It must be acknowledged that several criticisms linked to each study design allows to raise some doubts on the generalizability of their conclusions. In the DIAD study, conducted in USA and Canada, 1,123 T2DM participants asymptomatic for CAD were randomly assigned to screening by adenosine (99) Tc (m)sestamibi myocardial perfusion imaging, and followed-up for 5 years $[11,100]$. The number of cardiac events, that included non-fatal MI and cardiac death, was non-significant between screened (events $n=15$ ) and non-screened (events $n=17$ ) subjects (HR 0.88, 95\% CI 0.44-1.8, log-rank 0.12; $P=0.73$ ). The entity of cardiac event rate observed in the DIAD study was very low ( $0.6 \%$ per year), as also underlined by the authors, who quote, as a comparison, the rate observed in the subgroup of T2DM patients without previous cardiac events enrolled in the ACCORD, equal to 1.4\% event per year [119]. In the more recent CVD-REAL (The Comparative Effectiveness of Cardiovascular Outcomes) Nordic Study, referring to data obtained from national registries of Denmark, Sweden and Norway, for example, major adverse cardiovascular event rate (cardiovascular mortality, myocardial infarction, or stroke) was 2.12 per 100 patients-year, in T2DM subjects, new users of non-SGLT2 inhibitors glucose lowering drugs [120]. Therefore, patient selection in the DIAD study could not reflect the real-world population of T2DM patients. Moreover, the low rate of 
events observed in the DIAD limits the statistical power of this study, and its capacity in excluding a true difference in the outcomes. In addition, in the subgroup of subjects with moderate or large MPI defects, the number of cardiac events was significantly higher with respect to subjects with normal MPI or with fewer or minor MPI defects (HR 6.3, 95\% CI 1.9-20.1; $P=0.001$ ), suggesting a significant benefit of the screening, in patients with a more advanced disease.

The DYNAMIT study [51], a French multicenter RCT that included T2DM patients with other risk factors was prematurely discontinued because of difficulties in recruitment of patients; moreover, as in DIAD study, the event rate was lower than expected, and the insufficient statistical power of this trial invalidates its results.

Again, in FACTOR-64 a low number of cardiac events was observed (2.9\% in 4.8 years), probably due to the optimal medical management received by all the patients, as underlined by the authors; however, the evidence of CAD in the screened group was able to predict higher event rates [52].

The DADDY-D study is a single center Italian study aimed not only to screen silent myocardial ischemia by exercise tolerance testing (ETT) in at high risk T2DM, but also to treat patients by revascularization, when indicated [37]. This study failed to demonstrate that screening for asymptomatic CAD and revascularization favorably affects the occurrence of a first cardiac event. Anyway, as for other mentioned studies, these conclusions are biased by several limitations; first, the sample size was insufficient, with a female participant number lower than anticipated; secondly, the diagnostic test employed has a quite low sensitivity in detecting ischemia; and lastly, a reduced statistical power was implicit, due to an unexpectedly lower prevalence of positive tests.

Among all, only the study by Faglia et al. [40] was able to conclude that screening silent CAD in T2DM at high cardiovascular risk is effective in reducing future major cardiac events. These authors studied 71 subjects using exercise electrocardiogram test and dipyridamole stress echocardiography; if one of these tests was positive, the patient underwent a coronary angiography, and then surgical or percutaneous revascularization, if stenoses $\geq 50 \%$ of vessel diameter were present. The control group consisted in 70 non-screened T2DM subjects. During the mean follow-up period of 53.5 months, 1 major (myocardial infarction) and 3 minor events (angina) occurred in the screening arm, while 11 major and 4 minor events occurred in the control arm $(P$ of all events $=0.018)$.The conclusions of this paper are that: "The NNT of the study does indicate the feasibility of screening for unknown CAD in subjects with type 2 diabetes mellitus with high cardiovascular risk," also adding "economic cost does seem to be acceptable if the screening test consists in the sole use of dipyridamole stress echocardiography [40]."

These results are strengthen by a recent review and meta-analysis, by Beller et al. [121] who considered only studies performed with coronary CT angiography, in 5,012 asymptomatic diabetic individuals; these authors conclude that the presence of obstructive CAD (vs. nonobstructiveor no CAD) is a strong and independent predictor of cardiovascular events (HR 4.07, 95\% CI 2.30-7.21), with an increased HR also for non-obstructive plaque (vs. no CAD) of 2.17 (95\% CI 1.11-4.25).

To summarize, the interpretation of results from the studies aimed to demonstrate the usefulness of screening silent CAD in T2DM subjects cannot be univocal, and definitive, primarily depending on the level of risk of studied populations, and secondarily on the therapeutic management applied to patients.

\section{Final remarks and conclusions}

In the last 20 years, research has actively tried to answer the question whether it is useful or not to screen T2DM patients for silent CAD in terms of cost/benefit ratio, but a definitive indication is still lacking. The American Diabetes Association (ADA) guidelines recommend not screening asymptomatic diabetic patients for silent CAD [21]. The "2019 ESC Guidelines on diabetes, pre-diabetes, and cardiovascular diseases developed in collaboration with the European Association for the Study of Diabetes" equally do not recommend routine screening of CAD in asymptomatic diabetic subjects [19]; however, these guidelines suggest to apply a risk stratification approach, concluding that stress testing or computed tomography coronary angiography (CTCA) may be indicated in very high-risk asymptomatic individuals. Thus, coronary risk stratification represents a critical step in deciding whether or not to address a patient to screening. 
Criteria suggested by ESC Guidelines [19] and ADA Position statement [21] for considering the screening of CAD in type 2 asymptomatic diabetic patients are summarized (Table 3).

Table 3. Criteria suggested by ESC 2019 [19] and ADA 2020 [21] for considering the screening of CAD in type 2 asymptomatic diabetic patients

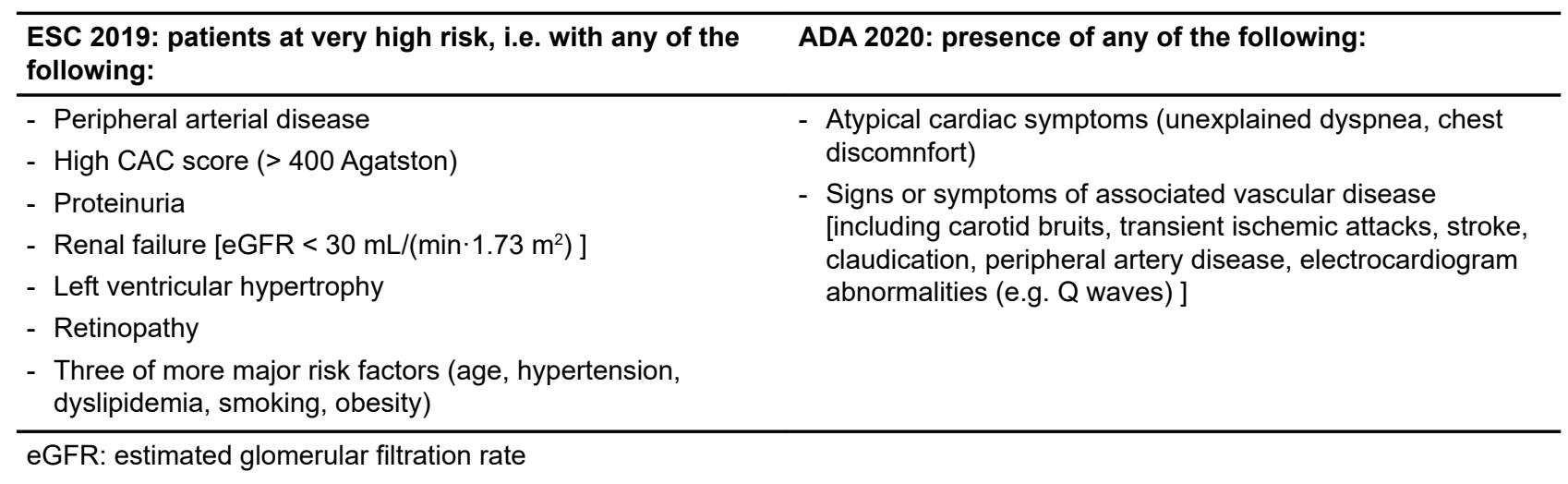

The treatment at target of all CV risk factors is currently universally considered the best approach for silent CAD in T2DM. Moreover, the benefits of revascularization in diabetic patients with silent CAD seem to be restricted to patients with severe CAD, who usually show also important comorbidities, such as chronic renal failure, left ventricular dysfunction and peripheral or carotid occlusive arterial disease. Available randomized trials have limitations and do not confirm the value of invasive treatment of ischemic heart disease $[122,123]$.

Therefore, the screening for silent CAD in asymptomatic T2DM patients still remains a possible approach to improve cardiovascular outcomes in this population, but until more large-scale, randomized trials are accomplished, no definitive conclusions can be drawn.

\section{Abbreviations}

ACCORD: the Action to Control Cardiovascular Risk in Diabetes

ADA: American Diabetes Association

BARDOT: the Basel Asymptomatic High-Risk Diabetics' Outcome Trial

CAC: coronary artery calcium

CAD: coronary artery disease

CAN: cardiac autonomic neuropathy

CV: cardiovascular

CVD: cardiovascular disease

DADDY-D: the Does coronary Atherosclerosis Deserve to be Diagnosed earlY in Diabetic patients?

DIAD: the Detection of Silent Myocardial Ischemia in Asymptomatic Diabetic Subjects

DYNAMIT: the Do You Need to Assess Myocardial Ischemia in Type-2 Diabetes

ECG: electrocardiogram

ESC: European Society of Cardiology

FACTOR-64: the Screening for Asymptomatic Obstructive Coronary Artery Disease Among High-Risk Diabetic Patients Using CT Angiography, Following Core 64 - FACTOR-64

MI: myocardial infarction

MiSAD: Milan Study on Atherosclerosis and Diabetes

MPI: myocardial perfusion imaging

MPS: myocardial perfusion test

SMI: silent myocardial ischemia 
SPECT: single photon emission computed tomography

T1DM: type 1 diabetes mellitus

T2DM: type 2 diabetes mellitus

UKPDS: the United Kingdom Prospective Diabetes Study

\section{Declarations}

\section{Author contributions}

The author contributed solely to the paper.

\section{Conflicts of interest}

The author declares that she has no conflicts of interest.

\section{Ethical approval}

Not applicable.

\section{Consent to participate}

Not applicable.

Consent to publication

Not applicable.

\section{Availability of data and materials}

Not applicable.

\section{Funding}

Not applicable.

\section{Copyright}

(c) The Author(s) 2021.

\section{References}

1. Center of disease control and prevention mortality database. Available from: https://www.cdc.gov

2. Gregg EW, Cheng YJ, Srinivasan M, Lin J, Geiss LS, Albright AL, et al. Trends in a cause-specific mortality among adults with and without diagnose diabetes in the USA: an epidemiological analysis of linked national survey and vital statistics. Lancet. 2018;391:2430-40.

3. $\mathrm{Xu} \mathrm{J}$, Zou MH. Molecular insights and therapeutic targets for diabetic endothelial dysfunction. Circulation. 2009;120:1266-86.

4. Nguyen MT, Pham I, Valensi P, Rousseau H, Vicaut E, Laguillier-Morizot C, et al. Flow-mediatedparadoxical vasoconstriction is independently associated with asymptomatic myocardial ischemia and coronary artery disease in type 2 diabetic patients. Cardiovasc Diabetol. 2014;13:20.

5. Rosen SD, Paulesu E, Nihoyannopoulos P, Tousoulis D, Frackowiak RSJ, Frith CD, et al. Silent ischemia as a central problem: regional brain activation compared in silent and painful myocardial ischemia. Ann Intern Med. 1996;124:939-49.

6. Langer A, Freeman MR, Josse RG, Armstrong PW. Metaiodobenzylguanidine imaging in diabetes mellitus: assessment of cardiac sympathetic denervation and its relation to autonomic dysfunction and silent myocardial ischemia. J Am Coll Cardiol. 1995;25:610-8. 
7. Mazzone A, Cusa C, Mazzucchelli I, Vezzoli M, Ottini E, Pacifici R, et al. Increased production of inflammatory cytokines in patients with silent myocardial ischemia. J Am Coll Cardiol. 2001;38:1895-901.

8. Milan Study on Atherosclerosis and Diabetes Group. Prevalence of unrecognized silent myocardial ischemia and its association with atherosclerotic factors in noninsulin-dependent diabetes mellitus. Am J Cardiol.1997;79:134-9.

9. Langer A, Freeman MR, Josse RG, Steiner G, Armstrong P. Detection of silent myocardial ischemia in diabetes mellitus. Am J Cardiol. 1991;67:1073-8.

10. Lee K, Jang H, Kim Y, Lee EJ, Choe YS, Choi Y, et al. Prognostic value of cardiac autonomic neuropathy independent and incremental to perfusion defects in patients with diabetes and suspected coronary artery disease. Am J Cardiol. 2003;92:1458-61.

11. Wackers FJ, Young LH, Inzucchi SE, Chyun DA, Davey JA, Barrett, EJ, et al. Detection of silent myocardial ischemia in asymptomatic diabetic subjects: the DIAD study. Diabetes Care. 2004;27:1954-61.

12. Cohn PF. Silent myocardial ischemia. Ann Intern Med. 1988;109:312-7.

13. Cohn PF, Fox KM, Daly C. Silent myocardial ischemia. Circulation. 2003;108:1263-77.

14. Thygesen K, Alpert JS, Jaffe AS, Chaitman BR, Bax JJ, Morrow DA, et al; Executive group on behalf of the joint European Society of Cardiology (ESC)/American College of Cardiology (ACC)/American Heart Association (AHA)/World Heart Federation (WHF) task force for the universal definition of myocardial infarction. Fourth universal definition of myocardial infarction. Circulation. 2018;138:e618-51.

15. Pride YB, Piccirillo BJ, Gibson CM. Prevalence, consequences, and implications for clinical trials of unrecognized myocardial infarction. Am J Cardiol. 2013;111:914-8.

16. Svane J, Pedersen-Bjerggard U, Tfelt-Hansen J. Diabetes and the risk of sudden cardiac death. Curr Cardiol Rep. 2020;22:112.

17. Scirica BM. Prevalence, incidence, and implications of silent myocardial infarctions in patients with diabetes mellitus. Circulation. 2013;127:965-7.

18. Valensi P, Lorgis L, Cottin Y. Prevalence, incidence, predictive factors and prognosis of silent myocardial infarction: a review of the literature. Arch Cardiovasc Dis. 2011;104:178-88.

19. Cosentino F, Grant PJ, Aboyans V, Bailey CJ, Ceriello A, Delgado V, et al; ESC scientific document group. 2019 ESC guidelines on diabetes, pre-diabetes, and cardiovascular diseases developed in collaboration with the EASD. Eur Heart J. 2020;41:255-323.

20. Bax JJ, Young LH, Frye RL, Bonow RO, Steinberg HO, Barrett EJ, et al. Screening for coronary artery disease in patients with diabetes. Diabetes Care. 2007;30:2729-36.

21. American Diabetes Association. Position statements. Cardiovascular disease and risk management: standards of medical care in diabetes-2020. Diabetes Care. 2020;43 Suppl 1:S111-34.

22. Pell S, D'Alonzo CA. Factors associated with long-term survival of diabetics. JAMA. 1970;214:1833-40.

23. Kannel WB. McGee L. Diabetes and cardiovascular disease: the Framingham study. JAMA. 1979;241:2035-8.

24. Herman JB, Medalic JH, Goldbourt U. Differences in cardiovascular morbidity and mortality between previously known and newly diagnosed adult diabetics. Diabetologia. 1977;13:229-34.

25. Nesto RW, Watson FS, Kowalchuk GJ, Zarich SW, Hill T, Lewis SM, et al. Silent myocardial ischemia and infarction in diabetics with peripheral vascular disease: assessment by dipyridamole thallium-201 scintigraphy. Am Heart J. 1990;120:1073-7.

26. Janand-Delenne B, Savin B, Habib G, Bory M, Vague P, Lassmann-Vague V. Silent myocardial ischemia in patients with diabetes: who to screen. Diabetes Care. 1999;22:1396-400. 
27. Inoguchi $\mathrm{T}$, Yamashita $\mathrm{T}$, Umeda $\mathrm{F}$, Mihara $\mathrm{H}$,Nakagaki O,Takada $\mathrm{K}$, et al. High incidence of silent myocardial ischemia in elderly patients with noninsulin-dependent diabetes mellitus. Diabetes Res Clin Pract. 2000;47:37-44.

28. Falcone C, Nespoli L, Geroldi D, Gazzaruso C, Buzzi MP, Auguadro C, et al. Silent myocardial ischemia in diabetic and nondiabetic patients with coronary artery disease. Int J Cardiol. 2003;90:219-27.

29. Araz M, Celen Z, Akdemir I, Okan V. Frequency of silent myocardial ischemia in type 2 diabetic patients and the relation with poor glycemic control. Acta Diabetol. 2004;41:38-43.

30. Margolis JR, Kannel WS, Feinleib M, Dawber TR, McNamara PM. Clinical features of unrecognized myocardial infarction-silent and symptomatic. Eighteenyear follow-up: the Framingham study. Am J Cardiol. 1973;32:1-7.

31. Kannel WB, Abbott RD. Incidence and prognosis of unrecognized myocardial infarction. An update on the Framingham study. N Engl J Med 1984;311:1144-7.

32. Kannel WB, Cupples LA, Gagnon DR. Incidence, precursors and prognosis of unrecognized myocardial infarction. Adv Cardiol. 1990;37:202-14.

33. Davis TME, Coleman RL, Holman RR; UKPDS Group. Prognostic significance of silent myocardial infarction in newly diagnosed type 2 diabetes mellitus: United Kingdom Prospective Diabetes Study (UKPDS) 79. Circulation. 2013;127:980-7.

34. Sheifer SE, Manollo TA, Gersh BJ. Unrecognized myocardial infarction. Ann Intern Med. 2001;135:801-11.

35. Bax JJ, Bonow RO, Tschöpe D, Inzucchi SE, Barret E; Global Dialogue Group for the Evaluation of Cardiovascular Risk in Patients With Diabetes. The potential of myocardial perfusion scintigraphy for risk stratification of asymptomatic patients with type 2 diabetes. J Am Coll Cardiol. 2006;48:754-60.

36. Miller TD, Rajagopalan N, Hodge DO, Frye RL, Gibbons RJ. Yield of stress single-photon emission computed tomography in asymptomatic patients with diabetes. Am Heart J. 2004;147:890-6.

37. Turrini F, Scarlini S, Mannucci C, Messora R, Giovanardi P, Magnavacchi P, et al. Does coronary atherosclerosis deserve to be diagnosed early in diabetic patients? The DADDY-D trial. screening diabetic patients for unknown coronary disease. Eur J Intern Med. 2015;26:407-13.

38. Marwick TH, Case C, Sawada S, Vasey C, Short L, Lauer M. Use of stress echocardiography to predict mortality in patients with diabetes and known or suspected coronary artery disease. Diabetes Care. 2002;25:1042-8.

39. RajagopalanN, Miller TD, Hodge DO, Frye RL, Gibbons RJ. Identifying high-risk asymptomatic diabetic patients who are candidates for screening stress single-photon emission computed tomography imaging. J Am Coll Cardiol. 2005;45:43-9.

40. Faglia E, Mantero M, Quarantiello A, Gino M, Curci V, Caminiti M, et al. Risk reduction of cardiac events by screening of unknown asymptomatic coronary artery disease in subjects with type 2 diabetes mellitus at high cardiovascular risk: an open-label randomized pilot study. Am Heart J. 2005;149:e1-6.

41. Budoff MJ, Raggi P, Beller GA, Berman DS, Druz RS, Malik S, et al. Noninvasive cardiovascular risk assessment of the asymptomatic diabetic patient: the imaging council of the american college of cardiology. JACC Cardiovasc Imaging. 2016;9:176-92.

42. Fox CS, Golden SH, Anderson C. Bray GA, Burke LE, de Boer IH, et al. Update on prevention of cardiovascular disease in adults with type 2 diabetes mellitus in light of recent evidence: a scientific statement from the american heart association and the american diabetes association. Diabetes Care. 2015;38:1777-803.

43. Cosson E, Paycha F, Paries J, Cattan S, Ramadan A, Meddah D, et al. Detecting silent coronary stenoses andstratifying cardiac risk in patients with diabetes: ECG stress test or exercise myocardial scintigraphy? Diabet Med. 2004;21:342-8.

44. Wackers FJT, Chyun DA, Young LH, Heller GV, Iskandrian AE, Davey JA, et al. Resolution of asymptomatic myocardial ischemia in patients with type 2 diabetes in the Detection of Ischemia in Asymptomatic Diabetics (DIAD) study. Diabetes Care. 2007;30:2892-8. 
45. Sultan A, Perriard F, Macioce V, Mariano-Goulart D, Boegner C, Daures JP, et al. Evolution of silent myocardial ischaemia prevalence and cardiovascular disease risk factor management in type 2 diabetes over a 10-year period: an observational study. Diabet Med. 2017;34:1244-51.

46. Zellweger MJ, Hachamovitch R, Kang X, Hayes SW, Friedman JD, Germano G, et al. Prognostic relevance of symptoms versus objective evidence of coronary artery disease in diabetic patients. Eur Heart J. 2004;25:543-50.

47. Anand DV, Lim E, Hopkins D, Corder R, Shaw LJ, Sharp P, et al. Risk stratification in uncomplicated type 2 diabetes: prospective evaluation of the combined use of coronary artery calcium imaging and selective myocardial perfusion scintigraphy. Eur Heart J. 2006;27:713-21.

48. DeLuca AJ, Kaplan S, Aronow WS, Sandhu R, Butt A, Akoybyan A, et al. Comparison of prevalence of unrecognized myocardial Infarction and of silent myocardial ischemia detected by a treadmill exercise sestamibi stress test in patients with versus without diabetes mellitus. Am J Cardiol. 2006;98:1045-6.

49. Zhang L, Li H, Zhang S, Jaacks LM, Li Y, Ji L. Silent myocardial ischemia detected by single photon emission computed tomography (SPECT) and risk of cardiac events among asymptomatic patients with type 2 diabetes: a meta-analysis of prospective studies. J Diabetes Complications. 2014;28:413-8.

50. Zellweger MJ, Maraun M, Osterhues HH, Keller U, Müller-Brand J, Jeger R, et al. Progression to overt or silent CAD in asymptomatic patients with diabetes mellitus at high coronary risk: main findings of the prospective multicenter BARDOT trial with a pilot randomized treatment substudy. JACC Cardiovasc Imaging. 2014;7:1001-10.

51. Lièvre MM, Moulin P, Thivolet $C$, Rodier M, Rigalleau V, Penfornis A, et al; the DYNAMIT investigators. Detection of silent myocardial ischemia in asymptomatic patients with diabetes: results of a randomized trial and meta-analysis assessing the effectiveness of systematic screening. Trials. 2011;12:23.

52. Muhlestein JB, Lappe DL, Lima JA, Rosen BD, May HT, Knight S et al. Effect of screening for coronary artery disease using CT angiography on mortality and cardiac events in high-risk patients with diabetes: the FACTOR-64 randomized clinical trial. JAMA. 2014;312:2234-43.

53. Il progetto cuore: calcolo del punteggio individuale. Available from: http://www.cuore.iss.it/ valutazione/carte

54. Blanchet Deverly A, Amaraa M, Larifla L, Velayoudom-Céphise FL, Roques F, Kangambega P, et al. Silent myocardial ischaemia and risk factors in a diabetic Afro-Caribbean population. Diabet Metab. 2011;37:533-9.

55. Zhu XR, Zhang HR, Li M, Zhou Z, Liu W, Lu J, et al. Risk of silent myocardial ischemia detected by single photon emission computed tomography (SPECT) among asymptomatic Chinese patients with type 2 diabetes. Medicine. 2019;98:e15618.

56. Ng MY, Zhou W, Vardhanabhuti V, Lee CH, Yu EYT, Wan EYF, et al. Cardiac magnetic resonance for asymptomatic patients with type 2 diabetes and cardiovascular high risk (CATCH): a pilot study. Cardiovasc Diabetol. 2020;19:42.

57. Prasad DS, Kabir Z, Revathi Devi K, Peter PS, Das BC. Prevalence and risk factors for silent myocardial ischemia (PRISM): a clinico observational study in patients of type 2 diabetes. Indian Heart Journal. 2019;71:400-5.

58. Deepti S, Roy A, Patel CD, Tandon N, Naik N, Singh S, et al. Assessment of asymptomatic ischemic heart disease using stress myocardial perfusion imaging in patients with type 2 diabetes Mellitus. Indian Heart J. 2018;70 Suppl 3:S157-60.

59. Al-Humaidi G, Sarikaya I, Elgazzar AH, Owunwanne A. Myocardial perfusion abnormalities in asymptomatic type 2 diabetic patients. J Saudi Heart Assoc. 2018;30:3-8.

60. Burgess DC, Hunt D, Li LP, Zannino D, Williamson W, Davis TME, et al. Incidence and predictors of silent myocardial infarction in type 2 diabetes and the effect of fenofibrate: an analysis from the Fenofibrate Intervention and Event Lowering in Diabetes (FIELD) study. Eur Heart J. 2010;31:92-9. 
61. Sigurdsson E, Thorgeirsson G, Sigvaldason H, Sigfusson N. Unrecognized myocardial infarction: epidemiology, clinical characteristics, and the prognostic role of angina pectoris: the Reykjavik Study. Ann Intern Med. 1995;122:96-102.

62. Kannel WB, Sorlie P, McNamara PM. Prognosis after initial myocardial infarction: the Framingham study. Am J Cardiol. 1979;44:53-9.

63. Choi EK, Koo BK, Kim HS, Cho YM, Kang HJ, Cho YS, et al. Prognostic significance of asymptomatic coronary artery disease in patients with diabetes and need for early revascularization therapy. Diabet Med. 2007;24:1003-11.

64. Davis TM, Fortun P, Mulder J, Davis WA, Bruce DG. Silent myocardial infarction and its prognosis in a community-based cohort of type 2 diabetic patients: the Fremantle Diabetes Study. Diabetologia. 2004;47:395-9.

65. Valensi P, Paries J, Brulport-Cerisier V, Torremocha F, Sachs R, Vanzetto G, et al. Predictive value of silent myocardial ischemia for cardiac events in diabetic patients: influence of age in a French multicenter study. Diabetes Care. 2005;28:2722-7.

66. Sejil S, Janand-Delenne B, Avierinos J, Habib G, Labastie N, Raccah D, et al. Six-year follow-up of a cohort of 203 patients with diabetes after screening for silent myocardial ischaemia. Diabet Med. 2006;23:1186-91.

67. Hamon M, Lemesle G, Meurice T, Tricot O, Lamblin N, Bauters C. Elective coronary revascularization in patients with stable coronary artery disease: incidence, determinants, and outcomes (from the CORONOR study). JACC Cardiovasc Interv. 2018;11:868-75

68. Valensi P, Meune C. Congestive heart failure caused by silent ischemia and silent myocardial infarction. Herz. 2019;44:210-7.

69. Kwong RY, Sattar H, Wu H, Vorobiof G, Gandla V, Steel K, et al. Incidence and prognostic implication of unrecognized myocardial scar characterized by cardiac magnetic resonance in diabetic patients without clinical evidence of myocardial infarction. Circulation. 2008;118:1011-20.

70. Colhoun HM, Betteridge DJ, Durrington PN, Hitman GA, Neil HAW, Livingstone SJ, et al. Primary prevention of cardiovascular disease with atorvastatin in type 2 diabetes in the Collaborative Atorvastatin Diabetes Study (CARDS): multicentre randomised placebo-controlled trial. Lancet. 2004;364:685-96.

71. Ostergren J, Poulter NR, Sever PS, Dahloef B, Wedel H, Beevers G, et al. The anglo-scandinavian cardiac outcomes trial: blood pressure-lowering limb: effects in patients with type II diabetes. J Hypertens. 2008;26:2103-11.

72. Erdmann E, Dormandy JA, Charbonnel B, Massi Benedetti M, Moules IK, Skene AM; PROactive Investigators. The effect of pioglitazone on recurrent myocardial infarction in 2,445 patients with type 2 diabetes and previous myocardial infarction: results from the PROactive (PROactive 05) Study. J Am Coll Cardiol. 2007;49:1772-80.

73. Dormandy JA, Charbonnel B, Eckland DJ, Erdmann E, Massi Benedetti M, Moules IK, et al. Secondary prevention of macrovascular events in patients with type 2 diabetes in the PROactive Study (PROspective pioglitazone Clinical Trial In macroVascular Events): a randomised controlled trial. Lancet. 2005;366:1279-89.

74. Chaitman BR, Hardison RM, Adler D, Gebhart S, Grogan M, Ocampo S, et al. The Bypass Angioplasty Revascularization Investigation 2 Diabetes randomized trial of different treatment strategies in type 2 diabetes mellitus with stable ischemic heart disease: impact of treatment strategy on cardiac mortality and myocardial infarction. Circulation. 2009;120:2529-40.

75. Frye RL, August P, Brooks MM, Hardison RM, Kelsey SF, MacGregor JM, et al; Group BDS. A randomized trial of therapies for type 2 diabetes and coronaryartery disease. N Engl J Med. 2009;360:2503-15. 
76. Ogawa H, Nakayama M, Morimoto T, Uemura S, Kanauchi M, Doi N, et al. Low dose aspirin for primary prevention of atherosclerotic events in patients with type 2 diabetes: a randomized controlled trial. JAMA. 2008;300:2134-41.

77. McDonald MR, Petrie MC, Home PD, Komajda M, Jones NP, Beck-Nielsen H, et al. Incidence and prevalence of unrecognized myocardial infarction in people with diabetes: a substudy of the Rosiglitazone Evaluated for Cardiac Outcomes and Regulation of Glycemia in Diabetes (RECORD) study. Diabetes Care. 2011;34:1394-6.

78. Aguilar D, Goldhaber SZ, Gans DJ, Levey AS, Porush JG, Lewis JB, et al. Clinically unrecognized Q-wave myocardial infarction in patients with diabetes mellitus, systemic hypertension, and nephropathy. Am J Cardiol. 2004;94:337-9.

79. Soejima H, Ogawa H, Morimoto T, Okada S, Sakuma M, Nakayama M, et al; JPAD Trial Investigators. One quarter of total myocardial infarctions are silent manifestation in patients with type 2 diabetes mellitus. J Cardiol. 2019;73:33-7.

80. Zinman B, Wanner C, Lachin JM, Fitchett D, Bluhmki E, Hantel S, et al; the EMPA-REG OUTCOME Investigators. Empagliflozin, cardiovascular outcomes, and mortality in type 2 diabetes. $\mathrm{N}$ Engl J Med. 2015;373:2117-28.

81. Marso SP, Daniels GH, Brown-Frandsen C, Kristensen P, Mann JFE, Nauck MA, et al; the LEADER Steering Committee on behalf of the LEADER Trial Investigators. Liraglutide and cardiovascular outcomes in type 2 diabetes. N Engl J Med. 2016;375:311-22.

82. Marso SP, Bain SC, Consoli A, Eliaschewitz FG, Jódar E, Leiter LA, et al; SUSTAIN-6 Investigators. Semaglutide and cardiovascular outcomes in patients with type 2 diabetes. N Engl J Med. 2016;375:1834-44.

83. Singleton MJ, German CA, Bertoni AG, Ambrosius WT, Bhave PD, Soliman EZ, et al. Association of silent myocardial infarction with major cardiovascular events in diabetes: the ACCORD trial. Diabetes Care. 2020;43:e45-6.

84. Sheifer SE, Gersh BJ, Yanez ND 3rd, Ades PA, Burke GL, Manolio TA. Prevalence, predisposing factors, and prognosis of clinically unrecognized myocardial infarction in the elderly. J Am Coll Cardiol. 2000;35:119-26.

85. Zhang ZM, Rautaharju PM, Prineas RJ, Rodriguez CJ, Loehr L, Rosamond WD, et al. Race and sex differences in the incidence and prognostic significance of silent myocardial infarction in the atherosclerosis risk in communities (ARIC) Study. Circulation. 2016;133:2141-8.

86. Stiles MC, Seaquist ER, Yale JF, Greenc JB, Katzd LA, Kempainene S, et al. Is silent myocardial infarction more common in women with type 2 diabetes than in men? J Diabetes Complications. 2012;26:118-22.

87. Canto JG, Rogers WJ, Goldberg RJ, Peterson ED, Wenger NK, Vaccarino V, et al; NRMI Investigators. Association of age and sex with myocardial infarction symptom presentation and in-hospital mortality. JAMA. 2012;307:813-22.

88. Canto JG, Goldberg RJ, Hand MM, Bonow RO, Sopko G, Pepine CJ, et al. Symptom presentation of women with acute coronary syndromes: myth vs reality. Arch Intern Med. 2007;167:2405-13.

89. Sato C, Wakabayashi K, Ikeda N, Honda Y, Sato K, Suzuki T, et al. Influence of sex on the incidence of potential coronary artery disease andlong-term outcomes in asymptomatic patients with diabetes mellitus. Int J Cardiol Heart Vasc. 2020;27:100504.

90. Scholte AJ, Schuijf JD, Kharagjitsingh AV, Dibbets-Schneider P, Stokkel MP, van der Wall E, et al. Prevalence and predictors of an abnormal stress myocardial perfusion study in asymptomatic patients with type 2 diabetes mellitus. Eur J Nucl Med Mol Imaging. 2009;36:567-75.

91. Tandon S, Frans JT, Wackers FJT, Inzucchi SE, Bansal S, Staib LH, et al; the DIAD Investigators. Genderbased divergence of cardiovascular outcomes in asymptomatic patients with type 2 diabetes: results from the DIAD study. Diab Vasc Dis Res. 2012;9:124-30. 
92. Vigili de Kreutzenberg S, Solini A, Vitolo E, Boi A, Bacci S, Cocozza S, et al. Silent coronary heart disease in patients with type 2 diabetes: application of a screening approach in a follow-up study. J Diabetes Complications. 2017;31:952-7.

93. Cosson E, Nguyen MT, Chanu B, Balta S, Takbou K, Valensi P. The report of male gender and retinopathy status improves the current consensus guidelines for the screening of myocardial ischemia in asymptomatic type 2 diabetic patients. Nutr Metab Cardiovasc Dis. 2013;23:557-65.

94. Simó R, Bañeras J, Hernández C, Rodríguez-Palomares J, Valente F, Gutierrez L, et al. Diabetic retinopathy as an independent predictor of subclinical cardiovascular disease: baseline results of the PRECISED study. BMJ Open Diabetes Res Care. 2019;7:e000845.

95. Vinik AI, Maser RE, Mitchell BD, Freeman R. Diabetic autonomic neuropathy. Diabetes Care. 2003;26:1553-79.

96. Pop-Busui R. Cardiac autonomic neuropathy in diabetes: a clinical perspective. Diabetes Care. 2010;33:434-41.

97. Dimitropoulos G, Tahrani AA, Stevens MJ. Cardiac autonomic neuropathy in patients with diabetes mellitus. World J Diabetes. 2014;5:17-39.

98. Maser RE, Mitchell BD, Vinik AI, Freeman R. The association between cardiovascular autonomic neuropathy and mortality in individuals with diabetes: a meta-analysis. Diabetes Care. 2003;26:1895-901.

99. Valensi P, Sachs RN, Harfouche B, Lormeau B, Paries J, Cosson E, et al. Predictive value of cardiac autonomic neuropathy in diabetic patients with or without silent myocardial ischemia. Diabetes Care. 2001;24:339-43.

100. Young LH, Wackers FJT, Chyun DA, Davey JA, Barrett EJ, Taillefer R, et al; the DIAD Investigators. Cardiac outcomes after screening for asymptomatic coronary artery disease in patients with type 2 diabetes: the DIAD Study: a randomized controlled trial. JAMA. 2009;301:1547-55.

101. Giovacchini G, Cappagli M, Carro S, Borrini S, Montepagani A, Rossella Leoncini R et al. Microalbuminuria predicts silent myocardial ischaemia in type 2 diabetes patients. Eur J Nucl Med Mol Imaging. 2013;40:548-57.

102. Emami T, Naeimei Z, Salehifard A, Azizmohammadi Z, Iranpour D, Kalantarhormozi M, et al. Significance of microalbuminuria in predicting silent myocardial ischemia in patients with type 2 diabetes using myocardial perfusion imaging. Mol Imaging Radionucl Ther. 2019;28:62-8.

103. Hussain Q Bukhari MH, Afzaal F, Fatima W. Microalbuminuria (Moderate Albumin Excretion) and its relationship with silent myocardial ischemia in treatment naïve type II diabetic patients. Pak J Med Sci. 2020;36:496-500.

104. De Vriese AS, Vandecasteele SJ, Van den BerghB, De Geeter FW. Should we screen for coronary artery disease in asymptomatic chronic dialysis patients? Kidney International. 2012;81:143-51.

105. Gazzaruso C, Solerte SB, Pujia A, Coppola A, Vezzoli M, Salvucci F, et al. Erectile dysfunction as a predictor of cardiovascular events and death in diabetic patients with angiographically proven asymptomatic coronary artery disease: a potential protective role for statins and 5-phosphodiesterase inhibitors. J Am Coll Cardiol. 2008;51:2040-4.

106. Gazzaruso C, Giordanetti S, De Amici E, Bertone G, Falcone C, Geroldi D, et al. Relationship between erectile dysfunction and silent myocardial ischemia in apparently uncomplicated type 2 diabetic patients. Circulation. 2004;110:22-6.

107. Shin D, Pregenzer G, Gardin JM. Erectile dysfunction: a disease marker for cardiovascular disease. Cardiol Rev. 2011;19:5-11.

108. Abdelhamed A, Hisasue S, Nada EA, Kassem AM, Abdel-Kareem M, Horie S. Relation between erectile dysfunction and silent myocardial ischemia in diabetic patients: a multidetector computed tomographic coronary angiographic study. Sex Med. 2016;4:e127-34. 
109. Gazzaruso C, Coppola A, Montalcini T, Valenti C, Garzaniti A, Pelissero G, et al. Erectile dysfunction can improve the effectiveness of the current guidelines for the screening for asymptomatic coronary artery disease indiabetes. Endocrine. 2011;40:273-9.

110. Zellweger MJ, Haaf P, Maraun M, Osterhues HH, Keller U, Müller-Brand J, et al; the BARDOT Investigators. Predictors and prognostic impact of silent coronary artery disease inasymptomatic high-risk patients with diabetes mellitus. Int J Cardiol. 2017;244:37-42.

111. Jeevarethinam A, Venuraju S, Dumo A, Ruano S, Mehta VS, Rosenthal M, et al. Relationship between carotid atherosclerosis and coronary artery calcification in asymptomatic diabetic patients: a prospective multicenter study. Clin Cardiol. 2017;40:752-58.

112. Mitevska IP, Baneva N, Bosevski M, Kostovska ES. Prevalence of risk factors and asymptomatic carotid atherosclerosis in diabetic patients screened for silent myocardial ischemia by SPECT myocardial imaging. Nucl Med Rev Cent East Eur. 2017;20:3-9.

113. Boulton AJ, Vinik AI, Arezzo JC, Bril V, Feldman EL, Freeman R, et al; American Diabetes Association. Diabetic neuropathies: a statement by the American Diabetes Association. Diabetes Care. 2005;28:956-62.

114. Kawano Y, Takemoto M, Mito T, Morisaki H, Tanaka A, Sakaki Y, et al. Silent myocardial ischemia in asymptomatic patients with type 2 diabetes mellitus without previous histories of cardiovascular disease. Int J Cardiol. 2016;216:151-5.

115. Rivellese AA, Piatti PM; Italian Intersociety Consensus Group. Consensus on: screening and therapy of coronary heart disease in diabetic patients. Nutr Metab Cardiovasc Dis. 2011;21:757-64.

116. Bauters C, Lemesle G. Screening for asymptomatic coronary artery disease in patients with diabetes mellitus: a systematic review and meta-analysis of randomized trials. BMC Cardiovasc Dis. 2016;16:90.

117. Clerc OF, Fuchs TA, Stehli J, Benz DC, Grani C, Messerli M, et al. Non-invasive screening for coronary artery disease in asymptomatic diabetic patients: a systematic review and meta-analysis of randomised controlled trials. Eur Heart J Cardiovasc Imaging. 2018;19:838-46.

118. Taylor F, Huffman MD, Macedo AF, Moore TH, Burke M, Smith GD, et al. Statins for the primary prevention of cardiovascular disease. Cochrane Database Syst Rev. 2013;2013:CD004816.

119. Gerstein HC, Miller ME, Byington RP, Goff DC, Bigger JT, Buse JB, et al; Actionto Control Cardiovascular Risk in Diabetes Study Group. Effects of intensive glucose lowering in type2 diabetes. N Engl J Med. 2008;358:2545-59.

120. Birkeland K, Jorgensen ME, Carstensen B, Persson F, Gulseth HL, Thuresson M, et al. Cardiovascular mortality and morbidity in patients with type 2 diabetes following initiation of sodium-glucose cotransporter-2 inhibitors versus other glucose-lowering drugs (CVD-REAL Nordic): a multinational observational analysis. Lancet Diabetes Endocrinol. 2017;5:709-17.

121. Beller E, Meinel FG, Schoeppe F, Kunz WG, Thierfelder KM, Hausleiter J, et al. Predictive value of coronary computed tomography angiography in asymptomatic individuals with diabetes mellitus: systematic review and meta-analysis. J Cardiovasc Comput Tomogr. 2018;12:320-8.

122. Phillips LM, Hachamovitch R, Berman DS, Iskandrian AE, Min JK, Picard MH, et al. Lessons learned from MPI and physiologic testing in randomized trials of stable ischemic heart disease: COURAGE, BARI 2D, FAME, and ISCHEMIA. J Nucl Cardiol. 2013;20:969-75.

123. Bittner V, Bertolet M, Felix RB, Farkouh ME, Goldberg S, Ramanathan KB, et al; BARI 2D Study Group. Comprehensive cardiovascular risk factor control improves survival: the BARI 2D trial. J Am Coll Cardiol. 2015;66:765-73. 